\title{
The alteration of first trimester screening markers in fresh and frozen-thawed blastocyst transfers
}

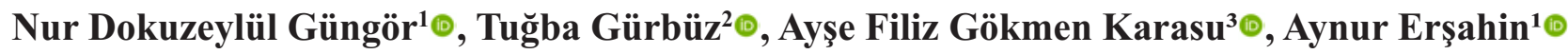 \\ ${ }^{1}$ Department of In Vitro Fertilization Center, Bahçeşehir University, Medical Park Göztepe Hospital, Istanbul, Turkey \\ ${ }^{2}$ Department of Gynecology and Obstetrics, Bahçeşehir University, Medical Park Göztepe Hospital, İstanbul, Turkey \\ ${ }^{3}$ Department of Gynecology and Obstetrics, Bezmialem University School of Medicine, İstanbul, Turkey
}

DOI: $10.18621 /$ eurj.400462

\begin{abstract}
Objectives: The aim of this study was to investigate whether first trimester combined screening for major fetal trisomies is influenced by assisted reproduction techniques (ART) from blastocyst transfer, with or without cryopreservation.

Methods: This study is a retrospective analysis involving 115 singleton pregnancies with euploid fetuses recruited between January 2017 and December 2017. Sixty-five women conceived with fresh blastocysts from in vitro fertilization (IVF) cycles (fresh-blasto), 50 with frozen-thawed blastocysts. All cases underwent ultrasound assessment at 11+0 - 13+6 weeks with measurements of crown rump length, nuchal translucency (NT), free beta-human chorionic gonadotrophin (free $\beta-h C G$ ) and pregnancy-associated plasma protein A (PAPP-A) concentrations.

Results: Baseline characteristics and pregnancy outcomes did not differ substantially among the study groups. The NT was not significantly different in the frozen-thawed -blasto compared to the fresh-blasto group ( $p=$ $0.741)$. The free $\beta$-hCG levels was not significantly different in frozen-thawed-blasto group compared to freshblasto group ( $p=0.495)$. The two groups showed no significant difference in the PAPP-A levels $(p=0,139)$. The median delta crown rump length was also not significantly different among the two groups $(p=0.758)$.

Conclusions: In ART pregnancies from blastocyst transfer, with or without cryopreservation, the NT measurement, free $\beta$-hCG concentration and PAPP-A levels did not show any significant difference. These features are apparently unrelated to the outcome of pregnancy and may be due to alterations or delays in embryogenesis or placentation with potential relevance for the screening test performance.
\end{abstract}

Keywords: Assisted reproductive technique, blastocyst, first trimester screening, frozen-thawed embryo transfer, fresh embryo transfer

Received: March 2, 2018; Accepted: March 21, 2018; Published Online: June 19, 2018

W omen with pregnancies achieved by assisted reproduction techniques (ART) are older than average and are therefore at higher risk for Down syndrome and other aneuploidies [1]. An effective screening test with a low false-positive rate (FPR) should be applied to these patients. Combined first trimester screening, utilizing maternal age, nuchal translucency (NT) measurement and maternal biochemistry (free beta-human chorionic gonadotrophin [free $\beta$-hCG] and pregnancy-associated 
plasma protein A [PAPP-A]), has been shown to detect $85-90 \%$ of cases with trisomy 21 and other major aneuploidies at a screen positive rate of 5-6\% [2-5].

In pregnancies affected by Down syndrome, maternal serum levels of PAPP-A are reduced [6] while free $\beta$-hCG subunits are elevated [7] in the first trimester. When combined with ultrasound measurement of NT, these two markers provide an effective means for screening for Down syndrome [811]. Maternal serum levels of PAPP-A and free $\beta$-hCG are affected by variables such as maternal cigarette smoking, parity, maternal weight and fetal gender [12, 13]. Studies also suggest a reduction in PAPP-A level in in vitro fertilization (IVF) pregnancies [14-17]. In IVF pregnancies, the currently largest explored group, an increase in free $\beta$-HCG and/or decrease in PAPP-A values have been reported [14, 15, 18-20].

In some studies, a relationship between unexplained elevations and reductions in maternal serum markers and obstetric complications has been reported [21, 22] . Therefore, altered first trimester serum concentrations in assisted-conception pregnancies could be an indicator of abnormal trophoblast invasion.

In the present study, we investigated the effects of fresh or frozen thawed embryo transfer on first trimester serum PAPP-A and free $\beta$-hCG levels.

\section{METHODS}

This retrospective study was approved by the Ethics Committee of Göztepe Medicalpark Hospital, Istanbul, Turkey (No: 2018/16). One hundred fifteen singleton pregnancies conceived by ART, who received combined first-trimester Down syndrome screening from January 2017 to December 2017 in IVF center.

Women who conceived with fresh or frozenthawed embryos from conventional IVF were referred to IVF center for counselling on the risk of fetal chromosomal disorders. Preimplantation genetic screening tests didn't performed in cases. All cases underwent ultrasound assessment at $11+0-13+6$ weeks with measurements of crown rump length (CRL), NT, free $\beta$-hCG and PAPP-A concentrations. Exclusion criteria were pregnancies with structural fetal malformations or aneuploidy, pregnancies resulting in miscarriage and stillbirth, singleton pregnancies following embryo reduction or spontaneous reduction of earlier multiple implantation. Those pregnancies with more than one gestational sacseen on ultrasound examination 5-6 weeks after theassisted reproduction procedure were excluded from thisstudy.

\section{Statistical Analysis}

Statistical analysis was performed using SPSS (Statistical Package for Social Sciences) software package version 17.0 for Windows. The Shapiro-Wilk test was used to determine the normality of data distribution. Significance of differences between the groups was determined by the non-parametric MannWhitney U-test. Differences in serum values and fetal NT were evaluated with the Kruskal-Wallis test. Significance was assumed at $p$ value of $<0.05$.

\section{RESULTS}

Table 1 summarizes the maternal age, maternal weight and gestational age at blood sampling of the

Table 1. Maternal characteristics and gestational age at sampling of the cases

\begin{tabular}{lccc}
\hline Parameters & $\begin{array}{c}\text { Fresh embryos } \\
\mathbf{n}=\mathbf{6 5}\end{array}$ & $\begin{array}{c}\text { Frozen embryos } \\
\mathbf{n}=\mathbf{5 0}\end{array}$ & p value* \\
\hline Maternal age (years) & $32.48 \pm 4.184$ & $31.86 \pm 4.83$ & 0.461 \\
Maternal weight at sampling (kg) & $65.67 \pm 1.56$ & $63.36 \pm 1.71$ & 0.231 \\
Gestational age at sampling (week) & $12.38 \pm 0.64$ & $12.17 \pm 0.68$ & 0.091 \\
Nuchal translucency & $1.44 \pm 0.51$ & $1.47 \pm 0.04$ & 0.741 \\
Crown rump length & $58.9 \pm 0.97$ & $58.6 \pm 1.17$ & 0.758 \\
\hline
\end{tabular}

Data are shown as mean \pm standard deviation. *The Shapiro-Wilk test was used to determine $p$ value. 
Table 2. PAPP-A and free $\beta$-hCG levels of the cases

\begin{tabular}{|c|c|c|c|}
\hline Parameters & $\begin{array}{c}\text { Fresh embryos } \\
\quad \mathrm{n}=65\end{array}$ & $\begin{array}{c}\text { Frozen embryos } \\
\mathbf{n}=\mathbf{5 0} \\
\end{array}$ & p value* \\
\hline Free $\beta$-hCG levels (IU/L) & $36.39 \pm 4.29$ & $35.87 \pm 4.71$ & 0.495 \\
\hline PAPP-A levels (IU/L) & $3.24 \pm 0.40$ & $2.74 \pm 0.32$ & 0.139 \\
\hline
\end{tabular}

cases and controls. Baseline characteristics maternal age $(p=0.461)$, maternal weight at sampling ( $p=$ $0.231)$ and gestational age at sampling $(p=0.091)$ did not differ significantly among the study groups. The NT was not significantly different in the frozenthawed -blasto compared to the fresh-blasto group ( $p$ $=0.741)$. The free $\beta$-hCG levels (IU/L) was not significantly different in frozen-thawed -blasto group compared to fresh-blasto group ( $p=0.495)$. The two groups showed no significant differences in the PAPPA levels $(\mathrm{IU} / \mathrm{L})(p=0.139)$. The median delta CRL was also not significantly different among the two groups $(p=0.758)$. Table 2 shows the PAPP-A multiple of the median (MoM) and free $\beta$-hCG MoM of the cases.

\section{DISCUSSION}

Biochemical markers (biomarkers) are serum proteins synthesized by placenta (PAPP-A, free $\beta$ $\mathrm{hCG}, \mathrm{hCG}$ and unconjugated estriol [uE3]) and by the fetus (alpha fetoprotein [AFP]). Whereas a reduced maternal serum level of AFP in second trimester is caused by defective differentiation of the fetal liver in Down's syndrome fetuses [23] the changes in the levels of placenta-derived proteins have not been explained.

IVF is normally performed after controlled ovarian hyperstimulation, which results in marked endocrine changes related to maturation of multiple follicles and later development of multiple corpora lutea. These endocrine changes may have a negative effect on implantation and early pregnancy, including changes in the level of biomarkers for genetic diagnostic testing. In contrast to fresh IVF cycles, frozen-thawed blastocysts (FET) is usually performed in natural or mildly stimulated cycles, which may affect the level of first trimester serum markers differently.

This study examined the different effects of transfer type (fresh vs frozen-thawed) of embryos on PAPP-A and free $\beta$-hCG levels between $11+0$ to $13+6$ weeks. We found no significant reduction of PAPP-A concentration in pregnancies conceived either with fresh or FET.

In the first trimester, PAPP-A is the most effective serum marker for fetal Down syndrome, both in combined and integrated screening [24]. In ART pregnancies, the reduced PAPP-A concentration is likely to result in a high FPR during screening.

Mode of fertilization, culture media and culture conditions are some aspects of the fertility treatment which may affect the embryo, implantation and early pregnancy [25]. Lower PAPP-A has been reported regardless of whether the cause of infertility was due to the male, female, or both. The pathophysiological basis for this reduction in PAPP-A levels after ART pregnancies when compared with natural pregnancies is still not known. A placental problem is the most likely explanation for the observed biochemical changes. PAPP-A and $\beta$-hCG are both produced in the placenta. A delayed placental maturation induced by the infertility itself [26] the drugs used for ovarian stimulation, laboratory manipulation, or all of these factors seem to be suitable explanations for these changes.Infertility itself or its severity can be directly related to these findings. In fact, Ranta et al. [26] found that PAPP-A values were significantly reduced in pregnancies conceived naturally after a time to pregnancy greater than 2 years compared with those conceived after a shorter time. This shows that infertility itself could be responsible for these biochemical changes. NT is unaffected by the mode 
of conception. Singleton pregnancies achieved by IVF and intracytoplasmic sperm injection (ICSI) with nondonor oocytes have reduced maternal serum PAPP-A and increased FPR, which are significant only in ICSI cycles. Pregnancies from frozen embryos with hormone therapy also show decreased PAPP-A, but without affecting the FPR. Elevated maternal serum free $\beta$-hCG levels in oocyte donation do not influence the FPR [27].

In ART pregnancies from blastocyst transfer, with or without cryopreservation, both the NT measurement and free $\beta$-hCG concentration are higher as compared to spontaneous conceptions, whereas PAPP-A does not show any significant difference. These features are apparently unrelated to the outcome of pregnancy and may be due to alterations or delays in embryogenesis or placentation with potential relevance for the screening test performance [28].

\section{CONCLUSION}

Today, the data on the effect of ART for the components of first trimester combined screening for chromosomal analysis are still controversial. In ART pregnancies from blastocyst transfer, with or without cryopreservation, NT measurement, free $\beta$-hCG concentration and PAPP-A levels did not show any significant difference. These features are apparently unrelated to the outcome of pregnancy and may be due to alterations or delays in embryogenesis or placentation with potential relevance for the screening test performance. While appropriate adjustment is necessary in applying this marker in the screening program for ART pregnancies, further studies are warranted to find out the cause for the lower PAPP-A level in pregnancies following ART.

\section{Ethics Committee Approval}

This retrospective study was approved by the Ethics Committee of Göztepe Medicalpark Hospital, Istanbul, Turkey.

\section{Authorship declaration}

All authors listed meet the authorship criteria according to the latest guidelines of the International Committee of Medical Journal Editors, and all authors are in agreement with the manuscript.

\section{Conflict of interest}

The authors disclosed no conflict of interest during the preparation or publication of this manuscript.

\section{Financing}

The authors disclosed that they did not receive any grant during conduction or writing of this study.

\section{REFERENCES}

[1] Anckaert E, Schiettecatte J, Sleurs E, Devroey P, Smitz J. First trimester screening for Down's syndrome after assisted reproductive technology: non-male factor infertility is associated with elevated free beta-human chorionic gonadotropin levels at 10-14 weeks of gestation. Fertil Steril 2008;90:1206-10.

[2] Krantz DA, Hallahan TW, Orlandi F, Buchanan P, Larsen JW, Macri JN. First-trimester Down syndrome screening using dried blood biochemistry and nuchal translucency. Obstet Gynecol 2000;96:207-13. [3] Spencer K, Nicolaides KH. Screening for trisomy 21 in twins using first trimester ultrasound and maternal serum biochemistry in a one-stop clinic: a review of three years experience. Br J Obstet Gynecol 2003;110:276-80.

[4] Spencer K, Souter V, Tul N, Snijders R, Nicolaides KH. A screening program for trisomy 21 at 10-14 weeks using fetal nuchal translucency, maternal serum free beta-human chorionic gonadotropin and pregnancyassociated plasma protein-A. Ultrasound Obstet Gynecol 1999;13:231-7. [5] Spencer K, Spencer CE, Power M, Dawson C, Nicolaides KH. Screening for chromosomal abnormalities in the first trimester using ultrasound and maternal serum biochemistry in a one-stop clinic: a review of three years prospective experience. Br J Obstet Gynecol 2003;110:281-6.

[6] Brambati B, Macintosh MC, Teisner B. Low maternal serum levels of pregnancy associated plasma protein A (PAPP-A) in the first trimester in association with abnormal fetal karyotype. Br J Obstet Gynaecol 1993;100:324-6.

[7] Brambati B, Tului L, Bonacchi I, Shrimanker K, Suzuki Y, Grudzinskas JG. Serum PAPP-A and free beta-hCG are firsttrimester screening markers for Down syndrome. Prenat Diagn 1994;14:1043-7. [8] Wald NJ, George L, Smith D, Densem JW, Petterson K. Serum screening for Down's syndrome between 8 and 14 weeks ofpregnancy. International prenatal screening research group. Br J Obstet Gynaecol 1996;103:407-12.

[9] Haddow JE, Palomaki GE, Knight GJ, Williams J, Miller WA, Johnson A. Screening of maternal serum for fetal Down'ssyndrome in the first trimester. N Engl J Med 1998;338:955-61.

[10] Spencer K. The influence of smoking on maternal serum PAPPA and free beta-hCG levels in the first trimester of pregnancy. Prenat Diagn 1999;19:1065-6.

[11] Bindra R, Heath V, Liao A, Spencer K, Nicolaides KH. One stop clinic for assessment of risk for trisomy 21 at 11-14 weeks: a prospective study of 15030 pregnancies. Ultrasound Obstet Gynecol 2002;20:21925.

[12] De Graaf IM, Cuckle HS, Pajkrt E, Leschot NJ, Bleker OP, van Lith JM. Co-variables in first trimester maternal serum screening. Prenat Diagn 2000;20:186-9.

[13] Niemimaa M, Heinonen S, Seppala M, Ryynanen M. The influence of smoking on the pregnancy-associated plasma protein A, free beta human chorionic gonadotrophin and nuchal translucency. BJOG 2003;110:664-7. 
[14] Liao AW, Heath V, Kametas N, Spencer K, Nicolaides KH. Firsttrimester screening for trisomy 21 in singleton pregnancies achieved by assisted reproduction. Hum Reprod 2001;16:1501-4.

[15] Maymon R, Shulman A. Serial first- and second-trimester Down's syndrome screening tests among IVF-versus naturally conceived singletons. Hum Reprod 2002;17:1081-5.

[16] Orlandi F, Rossi C, Allegra A. First trimester screening with free beta-hCG, PAPP-A and nuchal translucency in pregnancies conceived with assisted reproduction. Prenat Diagn 2002;22:718-21.

[17] Bersinger NA, Wunder D, Vanderlick F. Maternal serum levels of placental proteins after in vitro fertilisation and their implications for prenatal screening. Prenat Diagn 2004;24:471-7.

[18] Niemimaa M, Heinonen S, Seppala M, Hippelainen M, Martikainen H, Ryynanen M. First-trimester screening for Down's syndrome in invitro fertilization pregnancies. Fertil Steril 2001;76:1282-83.

[19] Maymon R, Shulman A. Integrated first- and second-trimester Down syndrome screening test among unaffected IVF pregnancies. Prenat Diagn 2004;24:125-9.

[20] Ghisoni L, Ferrazzi E, Castagna C, Levi Setti PE, Masini AC, PigniA. Prenatal diagnosis after ART success: the role of early combined screening tests in counselling pregnant patients. Placenta 2003;24:99103.

[21] Ong CY, Liao AW, Spencer K, Munim S, Nicolaides KH. First trimester maternal serum free beta human chorionic gonadotrophin and pregnancy associated plasma protein A as predictors of pregnancy complications. Br J Obstet Gynecol 2000;107:1265-70.

[22] Phil K, Larsen T, Krebs L, Christiansen M. First trimester maternal serum PAPP-A, $\beta$-hCG and ADAM12 in prediction of small-forgestational-age fetuses. Prenat Diagn 2008;28:1131-5.

[23] Chen H, Egan JO, Ohlu JF. Regulation and activities of alphafetoprotein. Crit Rev Eukaryot Gene Expr 1997;7:11-41.

[24] Gardner DK, Balaban B. Choosing between day 3 and day 5 embryo transfers. Clin Obstet Gynecol 2006;49:85-92.

[25] Dumoulin JC, Land JA, Van Montfoort AP, Nelissen EC, Coonen E, Derhaag JG, et al. Effect of in vitro culture of human embryos on birthweight of newborns, Hum Reprod 2010;25:605-12.

[26] Ranta JK, Raatikainen K, Romppanen J, Pulkki K, Heinonen S. Increased time-to-pregnancy and first trimester Down's syndrome screening. Hum Reprod 2010;25:412-7.

[27] Bellver J, Casanova C, Garrido N, Lara C, Remohí J, Pellicer A, et al. Additive effect of factors related to assisted conception on the reduction of maternal serum PAPP-A concentrations and the increasedfalse-positive rates in first-trimester Down syndrome screening. Fertil Steril 2013;100:1314-20.

[28] Cavoretto P, Dallagiovanna C, Vigano P, Somigliana E, Persico N, Papaleo E, et al. First trimester combined screening test in pregnancies derived from blastocyst transfer. Eur J Obstet Gynecol Reprod Biol 2016;198:50-5. 